\title{
FOTOGRAFÍAS DE FRONTERA EN EL NORTE GRANDE DE CHILE (1900-1970)*
}

\author{
PHOTOGRAPHS OF FRONTIER IN THE NORTH OF CHILE (1900-1970)
}

\author{
María Paz Bajas Irizar **
}

\begin{abstract}
Este artículo presenta algunas imágenes fotográficas correspondiente a las primeras décadas del siglo XX y producidas por diversos fotógrafos, muchas veces desconocidos, en contextos de frontera. El mundo andino en Chile comienza a configurarse luego de la anexión territorial tras la Guerra del Pacífico, motivo por el cual las representaciones fotográficas de los nuevos habitantes del norte del país reflejan la "chilenización" vivida hacia fines del siglo XIX y comienzos del siglo XX. Si bien a fines del siglo XIX existe una escasez de fotografías que den cuenta de este proceso cultural, durante las primeras décadas del siglo venidero es posible encontrar un número significativo de imágenes fotográficas. A partir de estos hallazgos es posible determinar que los procesos de fronterización también se expresan en las imágenes, las que registran una pronta incorporación de los retratados como sujetos partícipes de la nueva nación.
\end{abstract}

Palabras claves: fotografía, frontera, indígena, Guerra del Pacífico.

This article presents some photographic images from the first decades of the 20th century, made by different photographers, often unknown, in the frontier contexts. After the territorial annexation as a consequence of the War of the Pacific, the Andes world in Chile begins to take shape, reason why the photographic representations of the new inhabitants of the North of the country reflect the "chilenization" that was experienced towards the end of the 19th century and beginning of the 20th century. Even though at the end of the 19th century, there is a scarcity of photographs that give a testimony this cultural process, during the first decades of the coming century it is possible to find a significant number of photographic images. From these findings, it is possible to determine that the bordering processes are also expressed in the pictures, which recorded an early incorporation of the portrayed as partaking subjects of the new nation.

Key words: photography, frontier, indigenous, War of the Pacific.

\section{Introducción. Reflexiones sobre la frontera cultural en el Norte Grande}

La idea de frontera se vincula a un concepto multidimensional que comprende diversos significados, sin embargo, mayoritariamente es pensada como un límite territorial asociado a lo meramente militar relacionado al Estado, al territorio y a la población. Esto nos lleva a pensar que para que exista una frontera necesariamente debe existir un territorio y una población, junto con tener la función de demarcar diferencias y generar sentido. Además, a partir de la dimensión psicológica, la frontera se convierte en un orientador de las autopercepciones ejerciéndose el sentido de identidad y de comunidad, aludiendo a que los límites territoriales son parte de los procesos sociales y políticos (Zapata 2012). Para Grimson (2004) existirían dos tipos de fronteras, la cultural y la identitaria (sentimiento de pertenencia), dejando a un lado la idea de frontera como límite geográfico únicamente y realzando otras dimensiones ligadas a realidades que se construyen a partir de situaciones políticas y sociales.

Nos preguntamos: ¿Cómo se expresa la frontera cultural, en el caso del norte de Chile, a partir de la visualidad? Con la anexión territorial del límite norte tras la Guerra del Pacífico (1879-1883), donde el Estado operó como dispositivo institucional para ejercer soberanía territorial, nuevos grupos sociales y culturales son incorporados a una nueva nación y su consecuente territorio. Mirado desde la actualidad se podría pensar que se ha logrado un sentimiento de "hermandad" luego de más de un siglo de realizada la conquista bélica, generándose la idea de la interculturalidad donde dos o más pueblos fronterizos se sienten cercanos, hermanos, $\mathrm{y}$ donde se despliegan diversas manifestaciones culturales e identitarias. Sin embargo, hilando

\footnotetext{
* $\quad$ Proyecto FONDECYT N ${ }^{\circ} 1130478$.

** Universidad Católica de Chile, Instituto de Estética, Centro de Estudios en Antropología Visual (CEAVI), Santiago, Chile. Correo electrónico: mabajas@uc.cl
} 
más finamente, podemos constatar que la idea de hermandad oculta las dinámicas de "exclusión" e "integración" que incluyen la presencia del Estado como articulador de ambas.

Además, con el paso del tiempo, se generan cambios significativos en las relaciones sociales, económicas y geográficas donde la población resguardará algunos aspectos diferenciadores de su identidad, como lo referente a lo étnico (lengua, religiosidad, tradición, etc.). Sin embargo, todo grupo social y cultural se verá sometido a redefinir su identidad de acuerdo a las reconceptualizaciones de los espacios y los tiempos (Grimson 2004; Valhondo de la Luz 2010).

Es evidente la intervención política, económica y cultural del Estado chileno en su campaña por la anexión de territorios fronterizos tras la Guerra del Pacífico, lo que implicó una persecución de las poblaciones nativas que tenían como referente identitario a Perú, para el caso de las actuales regiones de Arica-Parinacota y de Tarapacá y Bolivia para la vigente Región de Antofagasta. Sin embargo, la ocupación de los territorios antes señalados se dio de manera diferenciada para cada región. En la primera de ellas se dio paso al arribo de un gran contingente de chilenos en ciudades como Tacna y Arica y sectores aledaños, gestándose una nueva administración de las urbes. Para la segunda, la ocupación del territorio entonces boliviano, se dio en febrero de 1879, donde Bolivia tuvo que ceder parte de su territorio. Así Chile, junto con ejercer soberanía, se ocuparía rápidamente de los yacimientos mineros que costearían parte de la guerra así como los procesos de escolarización llevados a cabo en el Norte Grande (Díaz et al. 2010a).

Junto con la ocupación comienzan a desarrollarse diferentes mecanismos de dominación que buscan asentar una nueva identidad chilena en oposición a las ya existentes. La llamada "chilenización" se manifestó mediante la construcción de elementos vinculados a la tradición con el fin de manipular a nivel simbólico a la población. Este concepto, para la región de Arica-Parinacota y Tarapacá, ha sido considerado a partir de dos ideas:

La primera alternativa se remite a acciones deliberadas conceptualmente percibidas, elaboradas y/o creadas por agentes estatales, políticos, periodistas, civiles o militares para definir las distintas políticas que llevó a cabo Chile durante el periodo del conflicto por los territorios de Tacna y Arica (1883-1929). La segunda opción apunta a despejar la conciencia nacional peruana de los pobladores del área de Arica abriendo paso a una nueva identificación nacional, en este caso la chilena (Díaz et al. 2010b:474).

En cualquiera de los dos casos, se buscaba la nacionalización chilena de una población con referentes identitarios peruanos. De este modo, el servicio militar, y sus múltiples posibilidades de adoctrinamiento (héroes, himnos, marchas que instalan fechas emblemáticas), se constituyó como un elemento fundamental en esta tarea nacionalista. El sistema educacional aportó en la transmisión de héroes y agentes patrios, así como también en la incorporación de valores, costumbres y actividades que formaran parte del sentido de pertenencia de lo chileno. Por ende, aportó con la homogenización de la sociedad nortina en general (Díaz et al. 2010a). Junto a esto, se instalaba la idea de la modernidad del Estado chileno donde “(...) Tarapacá como el resto de las provincias del país se vio envuelta en una iniciativa modernizadora que incluyo a la escuela fiscal como uno de sus aparatos más eficaces" (González 2002: 27).

Hay que considerar que para fines del siglo XIX se produjeron, en toda la Región, ordenamientos territoriales debido a los diversos conflictos entre los países (Guerra del Pacífico que involucró a Perú, Bolivia y Chile, o la Guerra de la Triple Alianza con Brasil, Uruguay, Argentina y Paraguay) así como internos (Conquista del Desierto para el caso argentino y Pacificación de la Araucanía para el chileno). Todo ello creó impactos en las hegemonías políticas y en los conceptos en torno al surgimiento de los Estados nacionales, además de impulsar las ideas de nacionalismo y militarismo. Estas concepciones sobre la nación surgen del pensamiento romántico europeo decimonónico, lo que llevó a la organización de las repúblicas mediante cuestiones territoriales y no étnicas. Es sintomático ver que los territorios en disputa contenían numerosos grupos étnicos que no fueron considerados o se los reconoce como una alteridad radical en relación al dominio blanco (Martínez et al. 2003).

Hacia fines del XIX y comienzos del XX, los discursos relacionados con la ocupación de la Región se actualizan y los imaginarios nacionales comienzan a vincularse con la existencia de población indígena, sobre todo en el caso de países como Bolivia y Ecuador. Es así que los discursos sobre la construcción de los Estados nacionales incluyen los discursos sobre los indígenas, "ya sea por su 
negación-invisibilización o por su supuesta emancipación [permitiendo] a las sociedades "mayoritarias" o "nacionales" construir un o unos imaginarios respecto del ser nacional" (Martínez et al. 2003: 210-211). De este modo, es posible sostener que el indígena no está ajeno en la construcción de nación, aun cuando ni siquiera fuera requerido para ello. Sin embargo, esta idea es una construcción política, militar e historiográfica usada por los grupos de poder para justificar el sentimiento patrio.

Específicamente para las regiones que aquí se estudian, la postguerra trajo consigo la construcción de imaginarios vinculados a la tradición campesina proveniente del valle central y de las urbes modernas e industrializadas, totalmente alejado de un norte salvaje, vacío y con características étnicas que nada tenían que ver con la modernidad homogeneizadora de la nación (Galdames et al. 2014). Junto con esto, la imagen que se creó de los indígenas, así como su representación, estará fuertemente influenciada por las nociones de racismo que orientan la construcción de un modelo único civilizatorio que se basa en una homogeneidad cultural alejada de todo elemento de barbarie. En definitiva, "lo que hicieron los estados nacionales y la elites latinoamericanas fue, en lugar de articular y reconocer las diferencias culturales, subordinarlas al centralismo homogeneizador" (Subercaseaux 2003:69).

A inicios del siglo XX, con el surgimiento del Estado de Bienestar, se comienza a pensar en la integración de nuevos sectores sociales, pero siempre bajo la lógica de la asimilación. En Latinoamérica, en general, comienza a surgir un discurso indoamericanista, aunque en Chile los dirigentes gustaban más de mirar hacia Europa que hacia sus pares americanos. A pesar de ello, es aquí cuando el sujeto indígena comienza a ser visto con nuevos ojos, donde se le reconoce una cultura con profundidad histórica convirtiéndola en una tradición anclada a un pasado precolombino, volviéndose un sujeto de valor patrimonial. Desde esta perspectiva, la idea de rescate cultural comienza a tomar fuerza. Por otra parte, a mediados del siglo XX, comienza una nueva manera de interpretar la realidad histórica de las culturas indígenas a la luz de las teorías contemporáneas. El movimiento indigenista influirá de manera decisiva en los nuevos modelos de comprensión de la sociedad occidental y de las sociedades indígenas en particular (Bajas 2014).

Un hito significativo es el primer Congreso Indigenista Interamericano realizado en la ciudad de Pátzcuaro, México, en 1940, donde participaron diversos Estados americanos y algunos representantes indígenas -como el mapuche Venancio Coñuepan quien fuera presidente de la Corporación Araucana y Diputado de la República-. A partir de esta reunión se comienza a gestar una política indigenista a nivel continental donde los Estados se comprometen a establecer una nueva relación con los pueblos originarios reconociendo su pertinencia cultural y la necesidad de integración de los mismos (Pineda 2012).

Otro encuentro relevante se desarrolla en Barbados en 1971. Un grupo de antropólogos, dentro de cuales destacan Miguel Alberto Bartolomé, Guillermo Bonfil Batalla, Darcy Ribeiro, entre otros, señalaron que el problema indio era responsabilidad de los Estados, las misiones religiosas y las ciencias sociales. Frente a esto consideraron que la única salida de los pueblos originarios era un trabajo desde adentro, donde se debiera experimentar en esquemas de autogobierno, sin tener que adaptarse a los esquemas políticos, económicos y sociales predominantes (Bajas 2014).

\section{Contexto Regional: EI Estado, los pueblos indígenas y su fotografía}

La relación entre el Estado nación y los grupos indígenas se vincula mayoritariamente a políticas de incorporación asumiendo los mismos derechos y deberes de la sociedad civil, lo que, en general, ha atentado contra el libre desarrollo de las prácticas culturales al ser sometidos y asimilados al grueso de la población mestiza. De esta manera, el intento de homogeneización ha provocado diversas confrontaciones a lo largo de la historia.

Este conflicto permanente se gestó en los albores de la conquista europea, luego con la constitución de las repúblicas se implementaron diversas "leyes para indios", las que estuvieron al servicio de los nuevos Estados nacionales y en detrimento de las poblaciones nativas.

Cabe destacar que las nacientes naciones hicieron uso de la figura del indio como símbolo de una identidad nacional a fines del siglo XIX y comienzos del XX, por ende, los indígenas "se volvieron sujetos de las formas de representación política del Estado y las formas simbólicas de la nación" (León 2010:43). Este proceso histórico, de dominación y de utilización de los grupos indígenas con fines políticos hacia la construcción de la identidad nacional, se basa en las 
raíces de la historia precolombina junto a la herencia naturalista europea que buscaba la vinculación del indígena con un entorno paradisíaco (Bajas 2014).

Luego del nacimiento de los Estados nacionales surge el indigenismo, entendido como el comienzo de un movimiento cultural y político que intenta rescatar una identidad indígena que difiere de la cultura occidental (Zapata 2003), pero también ha sido considerado un instrumento al servicio de los Estados nacionales para homogenizar la multiculturalidad reactualizando la situación colonial al interior de los pueblos indígenas (Fernández 1998).

En un primer momento, el desarrollo de las ideas ligadas al indigenismo estuvo orientado hacia un asistencialismo de la población indígena, posteriormente se buscó una participación donde hubiera una interlocución entre los indígenas y los sujetos constitutivos de la nación. A fines de 1980, el indigenismo era visto "como un resultado de la interrelación entre el crecimiento del movimiento indígena por una parte, y el desarrollo de la acción de los gobiernos por otra" (Anuario Indigenista 1988:7). Esto se debe a la notable revitalización de diversas culturas, al fortalecimiento de las identidades étnicas que han dado pie al masivo surgimiento de organizaciones locales, nacionales, regionales y continentales. Por lo tanto, a una recuperación de los modos de vida, prácticas culturales, derechos y defensa frente a una sociedad occidental que los ha homogeneizado con la utilización de la categoría de "indio", que dialoga con otras categorías raciales como "negro" -que despojó de identidades locales a las poblaciones africanas-; las categorías de "europeos" y "blancos" que unificó a las poblaciones dominantes; y finalmente aparece la categoría de "mestizo" como resultado de las relaciones entre las diversas identidades existentes (Quijano 2001).

El indigenismo no es el único proyecto que tuvo como centro de discusión al indígena. Junto con la llamada mundialización cultural, vía globalización, han surgido múltiples movimientos de identidades étnicas, hecho político más notable de las últimas décadas. Estos grupos rechazan la mestización que proponía el indigenismo, pues esto suponía la disolución de las lenguas y la occidentalización de los grupos indígenas. Así, "Las corrientes indianistas quieren conservar su lengua y su cultura, disponer de sus tierras y gobernarse de acuerdo con sus tradiciones y sus valores" (Altamirano 2008:25). Además, el indigenismo es visto, por los grupos étnicos, como un concepto de dominación y subordinación que utiliza el término "indígena" como prolongación de una relación desigual ante la cual se revelan utilizando el término "indio", revirtiéndole el contenido peyorativo para otorgarle un estatuto diferente frente a sus procesos de etnificación (Zapata 2003). "Si indio fue el nombre con el que nos han sometido, indio será el nombre con el que nos sublevaremos" (Primer Congreso de Movimientos Indios de Sud América, 1980:87).

El indigenismo, como un movimiento intelectual de larga data, pero con un referente activo entre los intelectuales de latinoamericana de mediados del siglo XIX es usado como un instrumento de protesta que persigue la inclusión del mundo indígena y el campesinado como elementos culturales a revalorizar. Destacan en esta labor Manuel González Prada con su texto Nuestros Indio de 1904, José Carlos Mariátegui con su texto El problema del Indio de 1928 y José María Arguedas con Agua, realizado en 1935, por nombrar algunos. Además, el indigenismo se aplica a todos los ámbitos del desarrollo cultural, expresándose también en los contextos iconográficos donde la figura del indio cobra cierta relevancia. Así, a través de grabados, pinturas, fotografías y cine se construyen imágenes visuales de "lo indígena" en función de necesidades particulares.

Para el caso que nos convoca en este estudio, es importante destacar la presencia de diversos fotógrafos franceses que arriban al Perú (Philognie Daviette, Furnier, A. de Lattre, Amic Gazan y Emile Garreud) a mediados del siglo XIX, cuando la fotografía experimentaba con las llamadas cartes de visite o "tarjeta de visita". De este modo, surgen fotógrafos locales como Manuel Atanasio Fuentes instalado en Lima, quien buscaban retratar la sociedad limeña en vinculación con lo europeo alejándose de lo indio y de esta manera ayudar en la construcción de un ideario nacional representado por "la elite criolla de la Lima moderna y civilizada" (Poole 2000:206).

Este panorama cambia con la presencia de Emile Garreaud, pues su influencia generó un cambio en el imaginario peruano integrando imágenes del indio, de lo rural y del mundo andino en general. Cabe destacar que también trabajó en Chile, instalando estudios fotográficos en ciudades como Copiapó, Santiago y Valparaíso. En 1875 se da inicio al auge de la fotografía especialmente en el Cusco, surgiendo fotógrafos como Luis Alviña, Miguel Chani, Luis Gismondi, José G. Gonzales y Juan Manuel Figueroa Aznar. Luego se daría 
origen a la Escuela Cusqueña de Fotografía donde se sumarían, a los ya mencionados, los nombres de Martín Chambi, Crisanto Cabrera, César Meza y Eulogio Nichiyama, entre otros, quienes comienzan a desarrollar una fotografía indigenista con un gran desarrollo estético y documental durante el siglo XX. Un hecho destacable fue la huelga universitaria llevada a cabo en 1909 en el Cusco, donde participaría la llamada "generación de La Sierra" que daría como resultado "la base de la intelectualidad y del futuro social del sur andino, pilares del fenómeno del 'indigenismo' cusqueño" (Trevisan y Massa 2009:47). Para Poole el indigenismo cusqueño fue influenciado por la historia precolombina y su estatus de capital incaica.

Al reclamar la historia y la geografía incas como propias, los indigenistas cusqueños introdujeron la olvidada figura del indígena andino contemporáneo en la literatura y la imaginación artística peruanas, así como en el discurso nacionalista, la jurisprudencia y la política interna (2000:224).

Al igual que Perú, la fotografía de Bolivia se inicia de la mano de extranjeros. Desde New Jersey los hermanos Charles y Jacob Ward recorrieron Chile, Perú y Bolivia, entre 1845 y 1848, tomando los primeros daguerrotipos de Bolivia. Sin embargo, el primer fotógrafo boliviano será Francisco Solano Ortega quien aprendiera del fotógrafo inglés William Helsby, pero dejaría tierras bolivianas para asentarse en Argentina, donde moriría en 1897. A raíz de esto quien surgiría como fotógrafo durante el siglo XIX sería Ricardo Villalba, quien incluiría al indígena dentro de sus retratos de estudio que circularían como carte de viste hacia 1872 en el mundo académico. En 1880 viajaría a París integrándose como parte de la sociedad francesa de fotografía. Para inicios del siglo $\mathrm{XX}$ aparecen quienes serán las figuras más relevantes de la fotografía en Bolivia: Luis Gismondi y Julio Cordero. El primero, nacido en Italia, abre un estudio fotográfico en La Paz, después de su paso por el Cusco, realizando un rescate de la cultura indígena. El segundo, boliviano, comienza de ayudante en el estudio fotográfico de los hermanos Valdez. Luego abre su propio estudio retratando a la sociedad paceña de la época. Siendo de origen aymara se inserta en el mundo social y logra combinar la fotografía popular y de ilustres personajes como los presidentes de Bolivia entre 1904 y 1937 (De Mesa 2008).

A estos podríamos sumar a Arturo Posnansky, de origen austriaco y llegado a Bolivia en 1896, quien utilizaría la fotografía para sus estudios arqueológicos (profesión que llevaría a cabo especialmente en Tiwanaku) por lo que tendría un fuerte componente científico antropológico. Además, durante los años '20, fundaría la compañía cinematográfica Cóndor Mayku Films, que comenzó realizando cortometrajes y reportajes, para después realizar el largometraje La gloria de la raza, que fue concebido como una gran producción artística del cine boliviano. Lo interesante de este arqueólogo fue su interés por estudiar al indígena boliviano realizando un importante registro antropológico del país (Bajas 2014).

En Chile, la fotografía se hace conocida a través de los franceses Daviette (1843) y Hulliel (1844), este último enseñaría sus conocimientos a José Dolores Fuenzalida, el primer daguerrotipista chileno que se instalaría en Santiago. Además, un norteamericano de nombre Robert H. Vance, divulga el daguerrotipo en las ciudades de Valparaíso, Santiago y Copiapó, entre los años 1847 y 1850. En esta última ciudad, la llamada "reina de la minería" por esos años, existían otros daguerrotipistas como los hermanos Ward (1847) y el chileno Francisco Sainz (1848). Cabe destacar, que también visitó países como Perú, Panamá y México, donde documentó restos arqueológicos, ciudades, naturaleza y monumentos (Alvarado y Csillag 2000; Rodríguez y Salgado 2010).

Durante la segunda mitad del siglo XIX, el daguerrotipo tendrá diversas figuras que se centrarán en realizar vistas de variadas ciudades, la construcción del ferrocarril o álbumes de familia. Luego se desarrolla el formato carte de viste, que por su bajo costo incentivó el coleccionismo y fue motivo de decoro en los salones de la alta sociedad. Si bien, para esta época existieron alrededor de 70 fotógrafos ${ }^{1}$, destaca la presencia de Emile Garreaud, quien llegado de Perú en 1861, se instala en Copiapó, luego en Santiago, Valparaíso, Talca y Concepción con diversos estudios fotográficos. A él le sucede su cuñado Félix Leblanc, quien conservó los estudios de Santiago y Valparaíso, asociándose con el hijo de Christian Enrique Valck (Jorge) en esta última ciudad. Precisamente de la mano de Valck padre es que se comienza a conocer la fotografía de los indígenas del sur de Chile, los mapuche. Llegado desde Alemania en 1852 se instala en Valdivia con una casa fotográfica retratando a la sociedad de la época así como a individuos y grupos de mapuche. Estos indígenas fueron retratados con la estética de fines de siglo donde se incorporaron telones y 
elementos que tuvieron la intención de generar una atmósfera étnica. En 1890, a pocos kilómetros, en la ciudad de Traiguén, se instala otro fotógrafo, el francés Gustavo Millet. Al igual que Valck, realiza retratos de familias acomodadas así como también de mapuche, incorporando el telón, la pose y el montaje, y desarrollando una "opción estética y un planteamiento poético y evocativo propio, que se articula a partir de la creación de una atmósfera expresiva producto de una construcción y un montaje cuidadosamente elaborado" (Alvarado 2001:18).

Otro fotógrafo que fotografía la zona sur de Chile es el canadiense Obder Heffer, quien fuera contratado por Leblanc en 1896. Luego se instala con su propio estudio en Santiago donde realizó vistas urbanas, imágenes de paisajes, personajes importantes de la sociedad, familias y damas de sociedad. Además, fotografió el mundo mapuche al interior de rukas (técnicamente complejo para los equipos fotográficos de la época) y de exteriores, donde se pueden advertir las actividades propias de la cultura. Junto a estas imágenes, este fotógrafo realiza imágenes de estudio donde hace uso de telones construyendo un sujeto étnico que ha sido integrado como parte del imaginario social respecto de los pueblos indígenas en Chile (Alvarado y Csillag 2000).

En el extremo austral de Chile, científicos, exploradores y fotógrafos como Joseph Payen y Jean-Luis Doze (Misión Científica del Cabo de Hornos 1882-1883), Julius Popper (1886), Lucas Bridges (1900-1908), W. Barclay (1900), Cándido Veiga (1900-1905), Charles W. Furlong (1907) entre otros, junto al sacerdote salesiano Alberto María de Agostini (1910-1918) y el sacerdote de la Congregación del Verbo Divino Martín Gusinde (1919-1924), fueron los encargados de fotografiar y construir un imaginario respecto de los indígenas del fin del mundo. Sin embargo, para el caso del Norte Grande de Chile el sujeto indígena no constituía parte del territorio, la alteridad estaba dada por un "otro" peruano o boliviano, y no por la presencia del indígena (Alvarado et al. 2007, 2012).

Como vemos, la fotografía ha sido usada como un elemento más en la construcción de los idearios nacionales, así como en la constitución de imaginarios sociales.

Indigenismo, hispanismo colonial y modernidad, configurarían la estructura cultural latinoamericana; desde acá resultan evidentes las tensiones generadas consciente e inconscientemente en la experiencia de los grupos identificados especialmente con alguno de estos componentes. Esta diversidad en tensión impide una amalgama homogénea del sujeto, el que en ocasiones puede verse en la necesidad de identificarse con uno de los elementos y en otras con otro, según sea el discurso dominante (Fondecyt $\mathrm{N}^{\mathrm{o}}$ 1130478).

\section{Fotografías de frontera en el Norte Grande (1900-1970)}

Existen numerosas reflexiones y análisis respecto de la constitución de la frontera en el denominado Norte Grande de Chile. La historia, la arqueología, la antropología, por nombrar solo algunas, se han dedicado a esta labor. Asimismo, existen algunos trabajos sobre ciertos aspectos visuales de este acontecimiento histórico, específicamente del conflicto bélico y los procesos sociales vinculados a la minería salitrera ${ }^{2}$.

Para el caso de este estudio, nos hemos centrado en aquellas imágenes que retratan el acontecer étnico de esos años y su transformación a partir de una nueva frontera establecida. Para ello nos hemos valido de un arduo trabajo de recopilación y sistematización de materiales fotográficos que forman parte de colecciones privadas y públicas nacionales e internacionales; y que bordean las 1.400 fotografías ingresadas a una base de datos ${ }^{3}$.

La fotografía es en sí misma un material documental y de registro de aspectos de la historia que posibilita el acceso a un discurso más amplio, a nuevos testimonios respecto de algunos aspectos de la realidad social no posibles de encontrar en otras fuentes. El análisis fotográfico nos hace adentrarnos no solo en los aspectos estéticos de la fotografía, sino que en sí misma es un artefacto visual que contiene un registro y variadas informaciones de carácter multidisciplinario (Báez 2009).

Dentro de las ciencias sociales, destaca la antropología en el uso de las imágenes como registro del trabajo de campo (Naranjo 2006), así como en el despliegue de una serie de modelos de análisis para estos materiales (Bateson y Mead 1942). Asimismo, y a partir de los planteamientos realizados por los estudios visuales, las imágenes son agentes activos de transformación y de mediación cultural considerando la situación de producción, el contexto de exhibición y recepción donde es consumida y significada (Mirzoeff 1998; Poole 2000; Berger 2002; Buck-Morss 2005). En este sentido, 
se hace pertinente la discusión sobre el supuesto carácter verídico de la fotografía, en tanto que ese tipo de imágenes estarían reproduciendo la realidad tal cual aparece frente al lente, tema que ha sido largamente discutido (Dubois 1986 y Alvarado et al. 2001; 2007; 2012).

A pesar de las discusiones teóricas sobre la veracidad de la fotografía, esta refleja una cierta realidad, en tanto el sujeto fotografiado estuvo frente al lente del fotógrafo. Idea planteada por Barthes (1989) cuando señalaba que la fotografía no se distingue de su referente, lo lleva consigo y ambos están marcados por esa inmovilidad, el hecho de estar siempre ahí. En este sentido, la fotografía de frontera se expresa mediante un referente que denota aspectos de esta fronterización.

Si nos centramos en los aspectos socioculturales, así como en los étnicos, podemos advertir diversos tipos de relaciones fronterizas mientras transcurría el siglo XX. Para el caso de Chile, Perú y Bolivia, que comparte una tradición étnica y cultura precolombina ${ }^{4}$ con fronteras culturales y simbólicas, al constituirse un nuevo escenario fronterizo post Guerra del Pacífico se generó una división de las poblaciones donde cada cual asumió una nación particular. Al suceder esta separación obligada y traumática, donde se dio un fuerte proceso de "chilenización" en el territorio nacional, el poblador fronterizo tuvo que tomar la decisión entre seguir perteneciendo a su "nación de origen", con la consecuente expulsión del nuevo territorio chileno, o adquirir una nueva identidad nacional y así permanecer en las tierras de costumbre. Quizás por esta razón es que, hacia fines del siglo XIX y las primeras décadas del siglo $\mathrm{XX}$, existe una escasa evidencia fotográfica de los indígenas de esta zona. Solo encontramos registros formales para trámites administrativos, donde los sujetos se someten a ser prontuariados siendo fichados y fotografiados bajo la estética de la fotografía de tipo carnet (frente y perfil) $)^{5}$. Para este tipo de fotografía, se hace uso de ciertos dispositivos visuales que implican "un conjunto de elementos conceptuales y materiales que maneja el fotógrafo, como operador, engarzados de tal forma que generan una imagen con una estética fotográfica específica" (Alvarado et al. 2007:23). En este caso, ambas imágenes son herederas de la fotografía antropométrica de mediados del siglo XIX, vinculada a la naciente antropología y su afán clasificatorio de "tipos humanos". Fueron sus capacidades de inscripción científica, obtenida bajo métodos fotométricos estandarizados de recuperación de datos morfológicos confiables y comparativos, las que posibilitaron su utilización en las prácticas de identificación de migrantes que tuvo su origen en la fotografía policial parisina de Alphonse Bertillon en 1885 (Poole 2000) (Figuras 1 y 2).

Otra expresión de la fotografía de frontera, y quizás la más significativa, fue aquella vinculada a los procesos educacionales. Como hemos visto, la creación de diversas escuelas fue fundamental en la campaña por la "chilenización" de las poblaciones de los territorios vencidos y anexados, lo que implicó el despojo y reemplazo de una cultura nacional por otra. Este tipo de frontera requirió de un largo tiempo para poder consolidarse, constituyéndose en un elemento político permanente en este proceso. Como sabemos, la fotografía es un sistema de representación y producción cultural que se asocia a diversas formaciones discursivas donde es posible observar la construcción de imaginarios

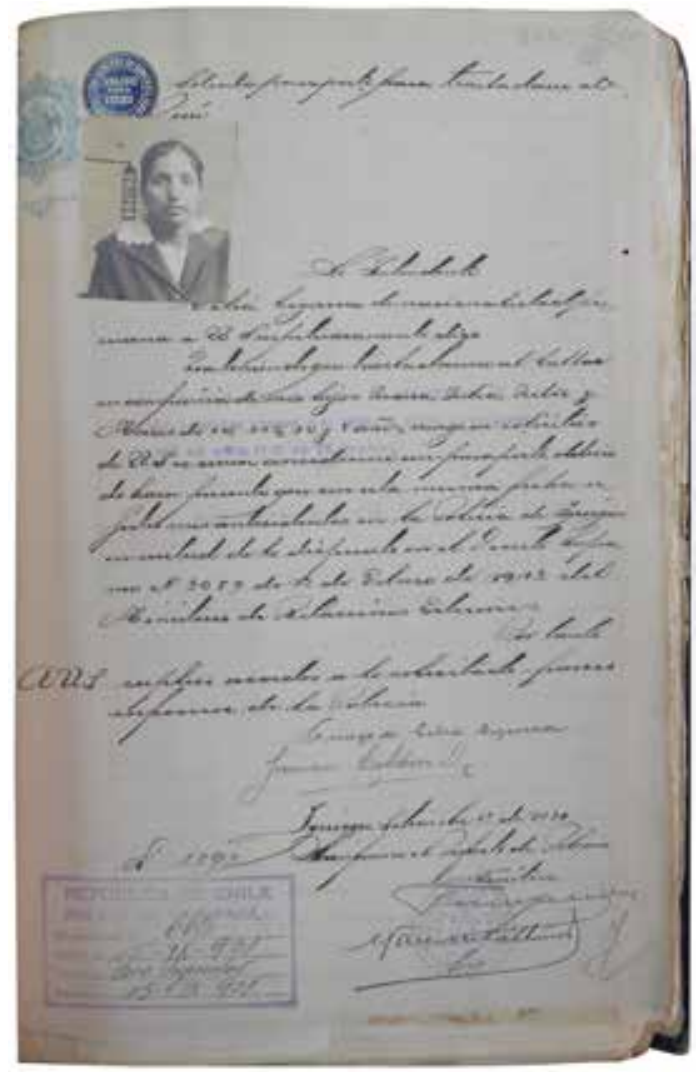

Figura 1. Fotógrafo desconocido. 1921. Solicitud de pasaporte con los datos manuscritos de la retratada. Solicitud y Notas Sueltas. Tomo 21-1921. Fondo Intendencia de Tarapacá. Archivo Regional, Universidad Arturo Prat, Iquique, Chile. 


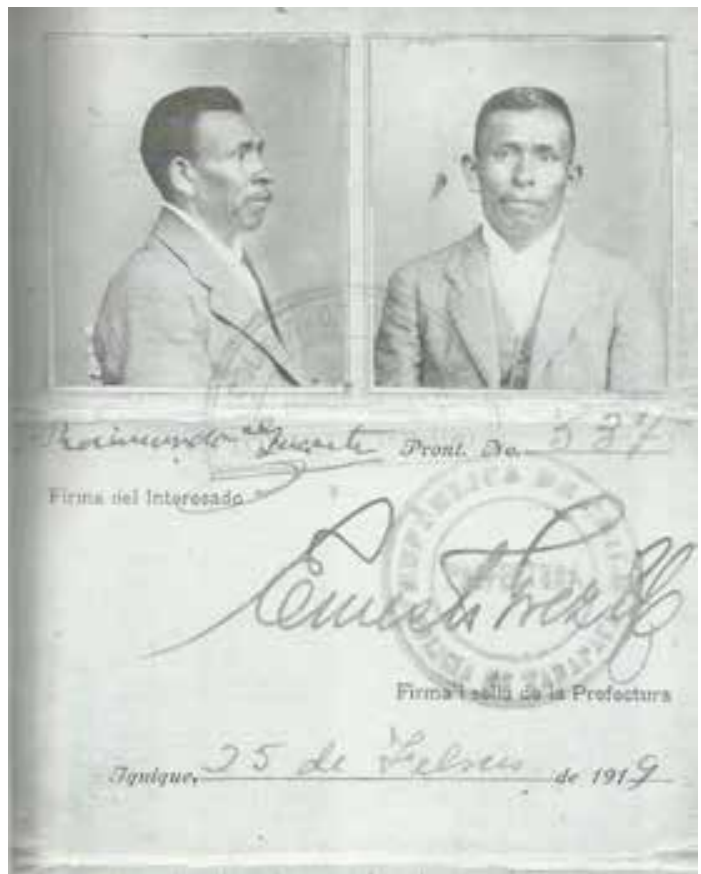

Figura 2. Fotógrafo desconocido. Raimundo Guacte Paicho, nacido en Pachica, aproximadamente en 1871. Salazar, M. 2002. Aimaras de la provincia de Iquique. Fondart. Iquique.

iconográficos en diversas épocas, contextos sociales y culturales. Para este caso, esta fotografía nos permite reflexionar acerca del uso de elementos simbólicos como la bandera nacional chilena y el ejercicio de adoctrinamiento de los educandos en un proceso de "aculturación" generado por la necesidad de instalar un ideario nacional chileno (Díaz et al. 2010a) (Figura 3).

Sumado a estas estrategias chilenizadoras, se instalan con fuerza las fronteras militares, donde se ejerció el dominio territorial con el emplazamiento de puestos fronterizos custodiados por el cuerpo militar de los vencedores. Esto implicó el adoctrinamiento de las poblaciones nativas que decidieron permanecer en sus territorios ancestrales, sin perjuicio de haber sido perseguidos y discriminados por su nueva condición de extranjeros. Para el caso de Atacama "El ejército chileno estableció -bajo el pretexto de tener un cordón sanitario que impidiera la propagación de un brote epidémico de cólera- destacamentos en Antofagasta de la Sierra, Pastos Grandes, Catua y Rosario(...) La localidad de Pastos Grandes fue el principal centro de operaciones de los militares chilenos" (Sanhueza 2001:67).

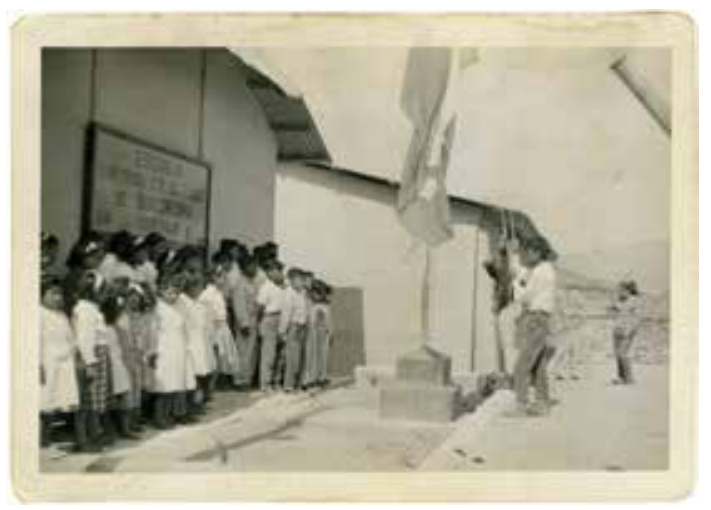

Figura 3. Rodomiro Huanca, 1966. Escuela de Socoroma, izando la bandera el día lunes al empezar las actividades. Colección particular de Rodomiro Huanca. Arica, Chile.

A pesar de lo anterior, las fronteras étnicas aparentemente parecieran ser las únicas que, si bien se vieron afectadas por la limitación de la trashumancia hacia los sectores aledaños que habían sido parte de un mismo territorio nacional, persisten hasta la actualidad más allá de las imposiciones fronterizas nacionales. Sin embargo, con el correr del siglo, es posible advertir que aun compartiendo una etnicidad, las prácticas culturales están diferenciadas y sus puntos de encuentro se ligan a "marcos de significación" propio de los actores. A partir de estas premisas es que es posible hablar de ciertas transformaciones a nivel de las significaciones y las acciones de las poblaciones que se vieron afectadas por la constitución de nuevas fronteras nacionales, pues aunque hayan sido creadas de manera artificiosa no implica que no sean poderosas (Grimson 2004).

Entrado el siglo XX, la fotografía se produce en contextos familiares, en el ámbito de lo privado, convirtiéndose en una fotografía íntima. Debido a la constitución de fronteras nacionales muchas familias fueron divididas, teniendo que recomenzar su historia familiar alejados de sus líneas parentales, lo que provocó que tales imágenes circularan en circuitos familiares transfronterizos, "transgrediendo" las fronteras políticas establecidas. Esto conllevó al surgimiento de fronteras étnicas que, más allá de las fronteras "reales", condujeron a que personas de una misma etnia comenzaran a transitar entre varios países ocupando las zonas fronterizas (Valhondo de la Luz 2010).

Durante el trabajo de campo se encontraron varias fotografías de estudio como la que incorporamos en esta reflexión. A diferencia de las demás, este tipo de 
imagen contiene diversos procedimientos visuales que corresponden a la decisión del fotógrafo frente a la imagen que quiere construir. De este modo, surge el uso de la pose como recurso fotográfico fundamental. Se asume una pose frente al lente, donde se ocupan gestos y actitudes relacionadas con el retrato, comparándose con un ejercicio de teatralidad (Alvarado et al. 2001). Sin embargo, una de las potencialidades de esta imagen, en contextos de frontera, está dada por el texto asociado. Imagen $y$ texto entregan informaciones diferentes, pero "lo relevante es ver que la relación entre estos dos textos (visual y escrito) funciona como una intensificación de cierta inercias teóricas respecto de las posibilidades de sentido de la imagen fotográfica" (Concha 2004:80). El texto refuerza la condición de proximidad parental de la imagen al inscribir al reverso: "Hijo Esteban, conserva este recuerdo que te dedica tu querida madre" (Figuras 4 y 5).

A pesar de la existencia de varias fotografías de estudio, en comparación con el universo investigado,

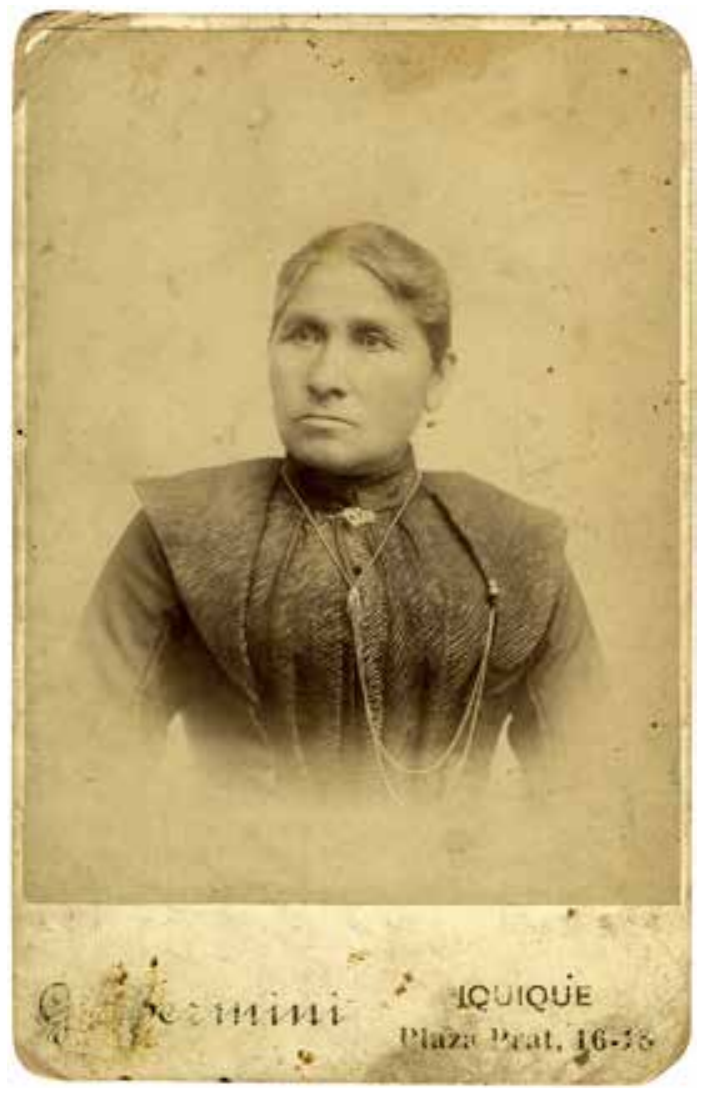

Figura 4. Fotógrafo desconocido, 1901. Abelina Cabezas Mamani. Oriunda de Cumiñaña. Colección particular de María Moscoso. Iquique, Chile.

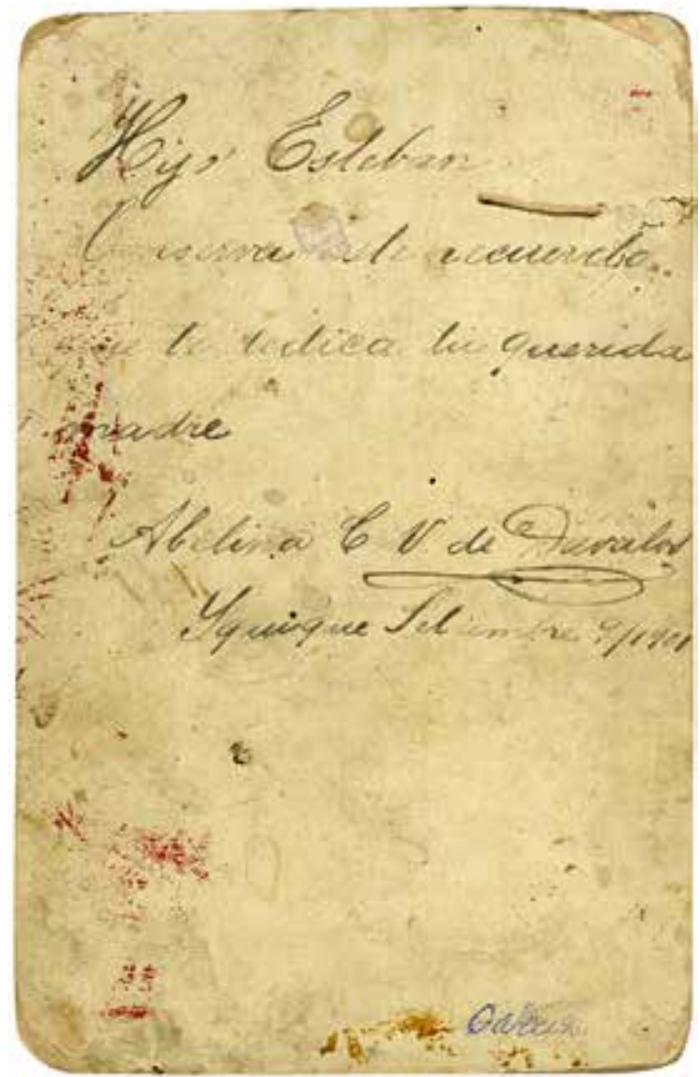

Figura 5. Inscripción al reverso de la fotografía: Hijo Esteban conserva este recuerdo que lo dedica tu querida madre. Abelina C. viuda de Dávalos.

este tipo de imágenes no tuvieron mayor potencial económico. A diferencia de otras regiones de Chile (fueguinos y mapuche), la fotografía de los indígenas del Norte Grande no tuvo mayor relevancia, no así aquella realizada en los campamentos mineros ${ }^{6}$ y las ciudades. Melquiades Pacha, nativo habitante de la localidad de Pachica, nos relató su experiencia como obrero en las salitreras. A través de este contacto pudimos constatar que el mundo indígena fue parte de esta actividad económica, pues las fotografías de los hombres de las salitreras invisibilizan los índices étnicos de estas poblaciones al ser incorporados como masa proletaria (Alvarado et al. 2012). Según su relato, los fotógrafos se internaban en la pampa salitrera con el propósito de encontrar clientes para fotografiar. Es así que Pacha se retrata y conserva, a sus avanzados años, esta fotografía de su vida en la salitrera. Si bien es una fotografía de exterior, conserva la estética de la foto de estudio al situar al fotografiado en el centro de la imagen utilizando 
la pared de la habitación como telón de fondo y posando frente al lente (Figura 6).

Dentro de la fotografía familiar, de comienzos del siglo XX, existen varios jóvenes indígenas invisibilizados por el traje militar en fotografías de estudio, algo que expresa la influencia de los cambios fronterizos. La fuerte "chilenización" realizada desde el Estado generó el surgimiento de "dos paradigmas complementarios en el proyecto nacional chileno: la relación entre los 'unos' (chilenos) y sus 'otros' (bolivianos y peruanos) y la supuesta noción de una homogeneidad constitutiva de lo chileno, social, cultural, étnica e incluso racialmente" (Lube y Garcés 2013:66). De este modo, el chileno se antepone al indígena, siendo el primero blanco, euro-descendiente y civilizado, versus el segundo que corresponde a lo bárbaro e incivilizado. Desde esta lógica, la adscripción militar logra asir al sujeto dentro del ideario nacional y mutilar su condición

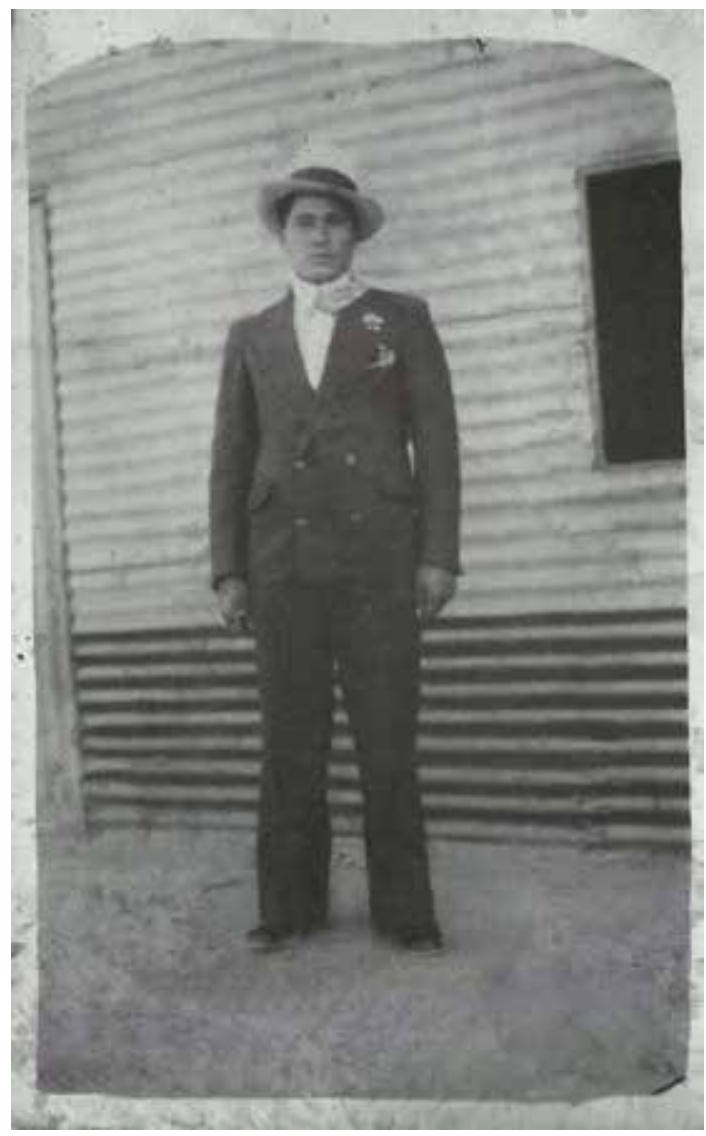

Figura 6. Fotógrafo desconocido, Melquiades Pacha Leandro, nacido en 1910 en Pachica. Salazar, M. 2004. Registro histórico fotográfico de la precordillera de provincia de Iquique (19001950). Fondart, Iquique. étnica primaria. La fotografía de este joven militar utiliza como procedimiento visual el recurso del telón y los objetos o parafernalia para generar una escenificación. Esto conduce a la construcción de modelos estéticos ligados a la fotografía de estudio, que para este caso busca enaltecer la condición de uniformado (Figura 7).

A partir de estas fotografías, hemos podido dar cuenta de la existencia de una frontera cultural visualizada, que si bien no ha tenido una prolífica circulación en la sociedad en general, sí ha sido parte de las historias familiares de los sujetos representados. Frente a esto podemos hablar de una circulación restringida, pero efectiva en la configuración de las identidades nacionales. Es probable que también influyeran en la posición, que en la actualidad, estas poblaciones tienen respecto de la posibilidad de dar acceso al mar a Bolivia (tema presente en la política exterior de ambos países). Existe un discurso unánime de negación, aludiendo a que la guerra aún está muy presente en la memoria y sentir de la

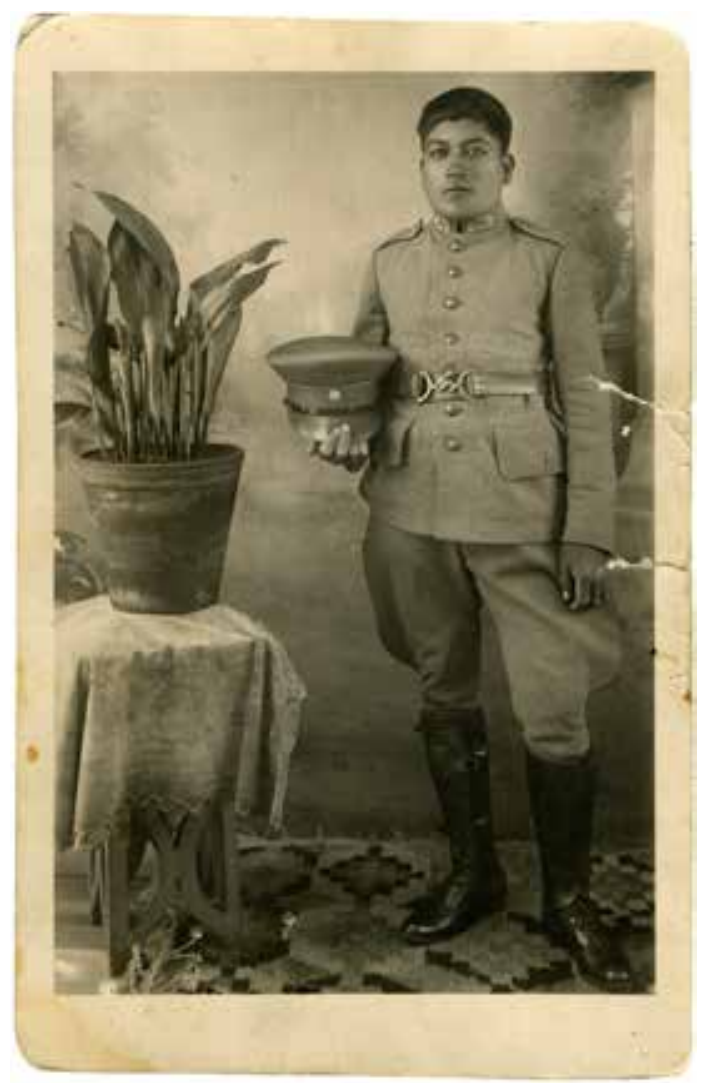

Figura 7. Fotógrafo desconocido, 1928. Antonio Capetillo Condore. Servicio Militar de Caballería. Colección particular de Carmen Capetillo. Iquique, Chile. 
gente, quienes no olvidan las muertes y procesos de desmembramiento familiar, demostrando que es una herida que aún no acaba de cerrar.

Frente a esta posición, pareciera quedar demostrada la idea de que la identificación nacional surge a partir de una construcción social y en virtud de una relación política. De esta forma, "la frontera ya no es material, sino simbólica, ya no es la línea de las aduanas, sino el límite de la identidad" (Grimson 2004:15).

\section{A modo de conclusión}

El espacio fronterizo del Norte Grande de Chile constituye un territorio donde interactúan diversos espacios nacionalidades así como identidades. Frontera que tiene su origen a partir de la constitución del Estado nación donde fue necesario el sometimiento de identidades preexistentes para construir el proyecto de integración nacional. $\mathrm{Si}$ bien esto se origina a comienzos del siglo XIX, esto continuará hasta la actualidad con más o menos presencia.

Sin embargo, las poblaciones fronterizas de los distintos países, han generado un circuito o red social que los diferencia de la demás población perteneciente a cada Estado nación. Por ende, las fronteras territoriales son el "resultado de un proceso dinámico, como una realidad construida política y socialmente y en permanente cambio en cuanto a su gestión de la movilidad humana" (Zapata 2012:40).

Si hablamos exclusivamente de la fotografía producida hacia fines del siglo XIX y comienzos del $\mathrm{XX}$, la evidencia muestra una escasa producción en comparación con otras etnias del país, considerando a los grupos culturales aimara, quechua, atacameños y changos. Esto se diferencia del discurso escrito, donde sí es posible hallar información sobre sus modos de vida y cultura. A partir de estudios arqueológicos y etnohistóricos se ha podido establecer la persistente relación de las poblaciones andinas. Al respecto Martínez (1998) ha señalado que,

Aunque entre las sociedades de los Andes centrales y aquellas del borde sur del altiplano, existan marcadas diferencias en sus grados de complejidad social, me parece que esa forma de accesos directos [a los diferentes pisos ecológicos], en el caso de las poblaciones del bloque más extremo del altiplano meridional, fue reemplazada por un conjunto de estrategias sociales y políticas que implicaban, ante todo, la interdigitación de poblaciones gracias a las relaciones sociales y de parentesco que ellas lograban establecer (Martínez 1998:38).

Como hemos señalado, este aparente "vacío" visual contrasta con los numerosos estudios que afirman la existencia de redes de intercambio de tecnologías, ideologías, mercancías y personas en tiempos prehispánicos y coloniales, algo que colaboró con la gran dispersión poblacional de estos territorios. Con la constitución de la República y posteriormente con la consolidación de los Estados nacionales las diferenciaciones étnicas se diluyen.

La idea de que todos los individuos serán tratados en iguales condiciones marcará un cambio importante, porque en la práctica la visión de los propios agentes del Estado fue la de tratarlos como obreros, campesinos, trabajadores de faena, pequeños productores, habitantes rurales, gente de la zona interior y no como indígenas (Bengoa 2004:185).

La "chilenización" vivida por la población de frontera es posible de advertir a través de algunas de las fotografías pesquisadas y analizadas en esta reflexión. La homogeneización de su población en contextos mineros mediante la invisibilización de sus índices étnicos, el uso de emblemas patrios para martillar en las conciencias la idea de nación mediante los espacios educacionales o la incorporación al ejército donde los sujetos indígenas exhiben sus uniformes en fotografías de estudio, son algunos de los ejemplos aquí señalados.

Si bien este estudio abarca hasta 1970, importante es señalar que a partir de la Ley indígena $\mathrm{N}^{\mathrm{o}} 19.253$, los grupos culturales antes señalados, a excepción de los changos, son considerados como poblaciones originarias, lo que les ha dado un nuevo estatus, generando una reetnificación y valoración identitaria. Por esta razón, a partir del 1990, existe una proliferación de la fotografía de los grupos étnicos del Norte Grande de Chile.

Esto ha llevado a un cambio de paradigma en términos de la visualidad de los grupos indígenas en el país, principalmente de los aquí señalados. Si antes hubo un aparente "vacío" visual, donde lo étnico estaba invisibilizado por el paisaje desértico y las construcciones nortinas (iglesias y plazas), apareciendo el indígena en los bordes del encuadre, en el presente las fotografías retratan la activa vida cultural y tradición andina de una población que se muestra más visual que nunca. Este "efecto icónico" hace que el indígena del Norte Grande vaya adquiriendo mayor relevancia en la fotografía a medida que se aproxima el siglo XXI, donde comienzan 
a visibilizarse aquellos índices étnicos silenciados (Alvarado et al. 2012).

Sin duda, esta gran cantidad de fotografías existentes a partir de mediados de los años '90 establecen un desafío para los análisis estéticos y antropológicos. Considerando la variable tecnológica y la nueva concepción visual de los propios retratados.

\section{Referencias Citadas}

Altmirano, C.

2008 La ciudad letrada, de la conquista al modernismo. En: Myers, J. (ed.). Historia de los intelectuales en América Latina, pp. 9-27.: Katz, Buenos Aires, Argentina.

Anuario Indigenista 1988 Indigenismo y participación, en Anuario Indigenista, Vol. XLVIII, pp. 7-13. México.

Alvarado, M. y Csillag, I.

2000 Historia de la fotografía en Chile. Rescate de huellas en la Luz. Centro Nacional del Patrimonio Fotográfico, Chile.

Alvarado, M.; P. Mege y C. Báez (Ed.)

2001 Mapuche: fotografías siglos XIX y XX: construcción y montaje de un imaginario. Pehuén Editores, Santiago, Chile.

Alvarado, M. y Mason, P.

2005 "Fuegia Fashion. Fotografía, indumentaria y etnicidad". En Revista Chilena de Antropología Visual. № 6, pp. 2-18. Santiago.

Alvarado, M.; Odone, C.; Maturana, F. y Fiore D. (Ed.)

2007 Fueguinos. Fotografía siglos XIX y XX. Imágenes e Imaginarios del Fin del Mundo. Pehuén Editores, Santiago, Chile.

Alvarado, M.; Mege, P.; Bajas M.P. y Möller C. (Ed)

2012 Andinos. Fotografías de los Siglos XIX y XX. Visualidades e imaginario del desierto y el altiplano. Pehuén Editores, Santiago, Chile.

Báez, C.

2009 Más allá de las imágenes. Fotografías de fueguinos y patagones en contextos de exhibición (1878-1898). Tesis para optar al grado de Doctor en Historia. Facultad de Historia, Geografía y Ciencia Política. Instituto de Historia, Pontificia Universidad Católica de Chile.

Bajas, M.P.

2014 Video indígena como estrategia para la construcción identitaria y la resistencia cultural. Los Casos de Chile, Bolivia y Ecuador. Tesis para optar al grado de Doctor en Estudios Americanos. Universidad de Santiago de Chile, Instituto de Estudios Avanzados-IDEA. Santiago, Chile.

Barthes, R.

1999 La cámara lúcida. Paidós, Barcelona.

Bateson, G. \& Mead, M.

1942 Balinese Character. A Photographic Analysis. New York Academy of Sciences, New York.

Bengoa, J. (Comp.)

2004 La memoria olvidada. Historia de los pueblos indígenas de Chile. Cuadernos Bicentenario, Santiago.

Buck-Morss, $\mathrm{S}$.

2005 Estudios Visuales e Imaginación Visual. En: Estudios visuales. La epistemología de la visualidad en la era de la globalización, editado por José Luis Brea, pp. 145-157. Ediciones Akal, Madrid.
Concha, J.P.

2004 Más allá del referente, fotografía. Del índex a la palabra. Colecciones Aisthesis, Instituto de Estética, Pontificia Universidad Católica de Chile.

Concha, J.P.; Alvarado, M.; Möller, C. y Bajas, M.P. 2012-2015 La debilidad del "sujeto latinoamericano" como tendencia fuerte en la fotografía documental mexicana, brasileña y andina, entre 1980 y 2012. Proyecto Fondecyt $\mathrm{N}^{\circ} 1130478$.

De Mesa, G.

2008 Proyecto de Graduación: Investigación Antropológica en el Carnaval de Oruro. Tesis para optar al grado de Licenciatura en Fotografía, Facultad de Diseño y Comunicación, Universidad de Palermo, Argentina.

Díaz, A.; Galdames, L. y Ruz, R.

2010a Nación e identidad en Los Andes. Indígenas de Arica y Estado chileno (1883-1929). Ediciones Universidad de Tarapacá, Arica, Chile.

Díaz, A.; Ruz, R. y Galdames, L.

2010b En los intersticios de la chilenidad. Antonio Mollo y las identidades en conflicto en Los Andes. Putre, 1900-1926. En Chungara. Revista de Antropología Chilena. Vol. 45, 3. 473-492.

Dubois, $\mathrm{P}$.

1986 El acto fotográfico. Paidós, Barcelona.

Fernández, J. M.

1998 Del indigenismo al indianismo: ¿cambio semántico o giro copernicano en la ideología y política indigenista interamericana? En América Latina en el umbral del siglo XXI, editado por F. Harto de Vera. CECAL, Madrid.

Galdames, L.; Ruz, R. y Meza, M.

2014 Imaginario nacional en revistas de la frontera norte de Chile post Guerra del Pacífico: ariqueña (Arica, 1923) y torbellino (Tacna, 1924). En Interciencia. Revista de Ciencia y Tecnología de América. Vol. 39. 7, 490-494.

González, S.

2002 Chilenizando a Tunupa. La escuela pública en el Tarapacá andino 1880-1990. Colección Sociedad y Cultura, Ediciones de la Dirección de Bibliotecas, Archivos y Museos, Santiago, Chile.

Grimson, A.

2004 Fronteras, naciones y región. Agenda pós-neoliberal. Fórum Social das Américas, pp. 1-28. Ibase, Action Aid Brasil, Attac Brasil e Fundação Rosa Luxemburgo, Quito, Ecuador. León, $\mathrm{C}$.

2010 Reinventando al otro. El documental indigenista en el Ecuador. Consejo Nacional de Cinematografía del Ecuador, Ecuador.

Lube, M. y Garcés, A.

2013 Circuitos migrantes. Itinerarios y formación de redes migratorias entre Perú, Bolivia, Chile y Argentina en el norte grande chileno. Revista Papeles de población 78:65-110. CIEAP/UAEM, México. 
Martínez, J.L.

1998 Pueblos del Chañar y el Algarrobo. Los atacamas en el siglo XVII. Ediciones de la Dirección de Bibliotecas, Archivos y Museos. Facultad de Filosofía y Humanidades, Universidad de Chile. Centro de investigaciones Diego Barros Arana. Santiago, Chile.

Martínez, N.; Martínez, JL. y Gallardo, V.

2003 Presencia y representación de los indios en la construcción de nuevos imaginarios nacionales (Argentina, Bolivia, Chile y Perú 1880-1920). En Nación, Estado y Cultura en América Latina, editado por A. Castillo, E. Muzzopappa, A. Salomone, B. Urrejola y C. Zapata, pp. 191-222. Ediciones Facultad de Filosofía y Humanidades, Universidad de Chile.

Mirzoeff, $\mathrm{N}$.

2003 Una introducción a la cultura visual. Paidós, Barcelona.

Naranjo, J.

2006 La fotografía, antropología y colonialismo (1845-2006). Editorial Gustavo Gili, SL., Barcelona.

Pineda, R.

2012 El Congreso Indigenista de Pátzcuaro, 1940, una nueva apertura en la política indigenista de las Américas. Baukara. Bitácoras de antropología e historia de la antropología en América Latina. 2: 10-28.

Poole, D.

2000 Visión, raza y modernidad. Una economía visual del mundo andino de imágenes. Sur Casa de Estudios del Socialismo, Lima. Primer Congreso de Movimientos Indios de Sud América. 1980. Ediciones MITKA, Perú.

Quijano, A.

2001 Colonialidad del poder. Cultura y conocimiento en América Latina. En: Capitalismo y geopolítica del conocimiento: El Eurocentrismo y la filosofía de la liberación en el debate intelectual contemporáneo, editado por W. Mignolo, pp. 117-132. Ediciones del Signo, Argentina.

Rodríguez, $\mathrm{H}$.

1985 Historia de la fotografía en Chile. Registro de daguerrotipistas, fotógrafos, reporteros gráficos y camarógrafos
1840-1940. Boletín de la Academia Chilena de la Historia. 96: 189-340.

Rodríguez, H. y Salgado, S.

2010 Chile a través de la fotografía. 1847-2010. Fundación

Mapfre, Taurus, Santillana Ediciones. España.

Salazar, M.

2002 Aimaras de la provincia de Iquique. Fondart. Iquique.

Salazar, M.

2004 Registro histórico fotográfico de la precordillera de provincia de Iquique (1900-1950). Fondart, Iquique.

Sanhueza, C.

2001 Las poblaciones de la Puna de Atacama y su relación con los estados nacionales. Una lectura desde el archivo. Revista de Historia Indígena. 5:55-82.

Subercaseaux, B.

2003 La construcción de la nación y la cuestión indígena. En Nación, Estado y Cultura en América Latina, editado por A. Castillo, E. Muzzopappa, A. Salomone, B. Urrejola y C. Zapata, pp. 69-80. Ediciones Facultad de Filosofía y Humanidades, Universidad de Chile, Chile.

Trevisan, P. y Massa, L.

2009 Fotografía cusqueña atravesando el indigenismo. Revista Aisthesis. 46: 39-64.

Valhondo de la Luz, J.

2010 Reflexiones sobre el concepto de fronteras. ETNICEX, 1:133-145. APEA. Asociación Profesional Extremeña de Antropología.

Zapata, C.

2003 Discurso indianista en México. Hacia una nueva representación del Estado Nacional, 1974-2000. En Nación, Estado y Cultura en América Latina, editado por A. Castillo, E. Muzzopappa, A. Salomone, B. Urrejola y C. Zapata, pp. 297-328. Chile, Ed. Facultad de Filosofía y Humanidades, Universidad de Chile.

Zapata, R.

2012 Teoría Política de la Frontera y la movilidad humana. Revista Española de Ciencia Política. 29: 39-66.

\section{Notas}

1 Cabe destacar que para el estallido de la Guerra del Pacífico, los fotógrafos Carlos Díaz y Eduardo Spencer, se unen para acompañar al ejército de Chile en la campaña hacia el norte. A partir de ello, construyen álbumes de la guerra donde retratan a oficiales, comandantes, hacen vistas de los campos de batalla y de los cuarteles. Según ha señalado Rodríguez, se los podría considerar como los primeros reporteros gráficos de Chile (Rodríguez 1985).

2 Para el caso de las fotografías referentes a la Guerra del Pacífico existen trabajos como: "La guerra de nuestra memoria: crónica ilustrada de la Guerra del Pacífico (1879-1884)" del peruano Renzo Babilonia y publicado por el Fondo Editorial de la Universidad de Ciencias y Humanidades (UCH) y editado por Fondo Editorial del Pedagógico San Marcos en 2008. Quien ya tenía trabajos anteriores como "Memoria de una invasión: La fotografía y la Guerra del Pacífico (1879-1884). Publicado por la Revista Pozo de Letras en el año 2005. Otra publicación es "Retratos: los héroes olvidados de la Guerra del Pacífico" de Mauricio Pelayo González, Christian Arce Godoy, Eduardo Gardella Brusco. RIL Editores, 2007. Y para el caso de análisis a las fotografías del mundo salitrero ver Sergio González, Pablo Miranda, Pedro Mege, entre otros.

3 Este trabajo fue realizado por un equipo multidisciplinario de historiadores, antropólogos, estetas y fotógrafos en el contexto del Fondecyt $\mathrm{N}^{\circ}$ 1060681. "La representación de las alteridades: fotografías de los indígenas del norte grande (1911-1990)", desarrollado entre los años 2006-2008.

4 Es importante considerar la existencia de circuitos de movilidad humana que datan, a lo menos, desde hace 10 mil años atrás, según datos arqueológicos e históricos. Esto revela que las migraciones son un fenómeno histórico en estas regiones.

5 La fotografía se incorpora al Estado en 1903 cuando se crea el Gabinete de identificación. En 1924 se hace obligatorio el uso de libreta de identificación que contiene el retrato de cada ciudadano, generándose la identificación de todo chileno (Rodríguez y Salgado 2010).

6 Durante las primeras décadas del siglo XX se dio una fuerte migración indígena hacia la industria minera, lo que implicó la invisibilización del indígena transformándose de manera gradual en obrero asalariado. 
